\title{
Application and Platform Design of Geospatial Big Data
}

\author{
Li Heng ${ }^{1,2,3, *}$, Huang $\mathrm{Wei}^{1}$, Zha Zhuhua ${ }^{1}$, Yang Jing ${ }^{1}$ \\ ${ }^{1}$ National Geomatics Center of China, Beijing, China-(liheng, huangwei, zhazh, yangjing)@ngcc.cn \\ ${ }^{2}$ Institute of Information Engineering, Chinese Academy of Sciences, Beijing, China \\ ${ }^{3}$ School of Cyber Security, University of Chinese Academy of Sciences, Beijing, China
}

\section{Commission IV, WG IV/7}

KEY WORDS: Geospatial big data, Geospatial big data application, Platform design, Geographic visualization, Spatiotemporal big data.

\begin{abstract}
:
With the wide application of Big Data, Artificial Intelligence and Internet of Things in geographic information technology and industry, geospatial big data arises at the historic moment. In addition to the traditional "5V" characteristics of big data, which are Volume, Velocity, Variety, Veracity and Valuable, geospatial big data also has the characteristics of "Location Attribute". At present, the study of geospatial big data are mainly concentrated in: knowledge mining and discovery of geospatial data, Spatiotemporal big data mining, the impact of geospatial big data on visualization, social perception and smart city, geospatial big data services for government decision-making support four aspects. Based on the connotation and extension of geospatial big data, this paper comprehensively defines geospatial big data comprehensively. The application of geospatial big data in location visualization, industrial thematic geographic information comprehensive service and geographic data science and knowledge service is introduced in detail. Furthermore, the key technologies and design indicators of the National Geospatial Big Data Platform are elaborated from the perspectives of infrastructure, functional requirements and non-functional requirements, and the design and application of the National Geospatial Public Service Big Data Platform are illustrated. The challenges and opportunities of geospatial big data are discussed from the perspectives of open resource sharing, management decision support and data security. Finally, the development trend and direction of geospatial big data are summarized and prospected, so as to build a high-quality geospatial big data platform and play a greater role in social public application services and administrative management decision-making.
\end{abstract}

\section{INTRODUCTION}

Geographical Information is an important basic and strategic information resource for the country, which involves economic and social development, ecological civilization construction, national security and people's life facilitation. It is playing an increasingly important role in digital economy, government decision-making, industrial development and people's life. With the development of Big Data, Artificial Intelligence and other technologies, the huge amount of geospatial data generating in the application of geographic information forms the rudimentary form of geospatial big data.

Scholars' studies on geospatial big data mainly focus on: Knowledge mining and discovery of geospatial data: academician Li Deren has took the lead in international research on the nature of geospatial data knowledge mining, pioneered the discovery of knowledge from GIS databases, and published the monograph "Spatial Data Mining Theory and Application" in 1995. Harvey proposed "Geographic Data Mining and Knowledge Discovery" for the first time in 2009. There is a paper which further expounds the characteristics of big data GIS from three aspects of GIS spatial data management, spatial data analysis and visualization (Li Qingquan et al., 2014). They put forward the concept of big data generalized GIS, and further elaborated the characteristics of big data GIS from the three aspects of GIS spatial data management, spatial data analysis and visualization. The integration trend of geographic computing, urban computing and social computing in the era of generalized GIS is forecasted (Lu Feng et al., 2014; Mccoy et al., Soille et al., 2017).

Spatiotemporal big data mining: Li Deren believes that spatiotemporal data mining is a process of automatically discovering and extracting implicit and non-visible patterns, rules and knowledge from massive and multi-source spatiotemporal big data. The techniques are analyzed to discover knowledge from spatial big data (Praveen et al., 2016), and to further make knowledge change into data intelligence (Wang Shuliang et al., 2013; Shekhar et al., 2015). Songnian Li classified and summarized the geographic big data mining methods from the perspective of mining targets in 2015. Bian Fuling discussed the latest research progress of spatial big data mining from two aspects of platform and algorithm in 2017. Another five attributes except for " $5 \mathrm{~V}$ ", including granularity, scope, density, skewness and precision, are summarized regarding geospatial big data (Mir et al., 2018; Pei Tao et al., 2019).

The impact of geospatial big data on visualization, social perception, smart city, etc: some people believe that the new technical features of geospatial big data will promote the new development of map synthesis, map visualization and map projection (Kramer et al., 2015; Ai Tinghua, 2016). Liu Yu believe that multi-source geographic big data provides an unprecedented means of social perception for the distribution pattern, interaction and dynamic evolution of geographical phenomena in 2018. Academicians such as Li Deren and Wang

\footnotetext{
* Corresponding author
} 
Jiayao believed that without geospatial big data, there would be no smart city.

Geospatial big data services for government decision-making support: Liu Jiping believes that geospatial big data technology oriented to e-government provided a new means for government information management and decision-making in 2014. The FogGIS (which is a geographic information system based on fog calculation method) is proposed to government geospatial health big data analysis and coastal risk adaptation (Rumson et al., 2017; Barik et al., 2016; Barik et al., 2019).

In brief, this paper is organized as follows: Section 2 gives the connotation of geospatial big data at first. Section 3 introduces the application of geospatial big data, while the key technologies and design are introduced in Section 4 which mainly contains the infrastructure, functional and nonfunctional basic requirements and indicators of the National Geospatial Big Data Platform, and gives a practical example. Section 5 summaries the opportunities and challenges of geospatial big data. We conclude our paper in Section 6 .

\section{CONCEPT OF GEOSPATIAL BIG DATA}

Geographical spatial scope of big data: including the geographic location of the geographical space (mainly refers to the surveying and mapping geographic information, without geography, geology) location data and business data, such as economy and society not only has the property of common data measured value $(\mathrm{V})$, but also contains the time $(\mathrm{T})$ and space $(\mathrm{X}$ $\mathrm{Y}, \mathrm{Z}$ ) information, with the characteristics of space, time, attributes, 3d. Geographical spatiotemporal data constitute the era of big data describing various features and phenomena of space frame and space benchmark (basic geographic information), moreover, contains the surface features and economic and social activities of time and space distribution. As an important data type, geographical spatiotemporal data has "5V" characteristics like as a traditional big data, and geographical "Location Attributes" (Location). It is mainly divided into two categories:

Geospatial basic big data: basic geospatial big data mainly includes vector data, raster data, map tile data and remote sensing image data from mapping and remote sensing. Basic geographic data as a unified framework of spatial orientation and spatial analysis, describes the measurement of the earth's surface control points, drainage, residents and facilities, traffic, pipeline, state and administrative region, landform, vegetation and soil, cadastral management, place names and other information of location, shape and properties on natural and social factors. Basic geographic data has become a kind of important geographic space based large data.

Geospatial applied big data: on the one hand, geospatial applied big data comes from industry data of natural resources, environment, water conservancy, public security, statistics and other departments, such as IoT sensor data collected by water, electrical or mining companies. On the other hand, through organic integration of basic geographic data with natural, cultural, economic and cultural data, it provides correct guidance and decision-making assistance for various industries and forms industrial economic data and historical and cultural data. For example, industrial economic data includes not only GIS, satellite positioning and navigation, aviation and aerospace remote sensing industrial economic data, but also LBS (Location-based Services), geographic information service and other industrial economic data. Historical and cultural data includes historical atlases and national maps.

It is worth mentioning that through the collection, fusion and aggregation of a certain volume of applied big data on the basis of geospatial basic big data, a complete geospatial big data is formed, which provides the basic data source for the following geospatial big data application, national spatial information infrastructure platform, project information system, etc.

\section{APPLICATIONS OF GEOSPATIAL BIG DATA}

The geospatial big data is widely used in the Internet, Mobile Internet, Internet of Things and other scenarios. At present, the application fields of geospatial big data are mainly divided into geospatial location visualization, industrial thematic geographic information integrated services, geographic data science and knowledge service research.

\subsection{Visualization of geospatial locations}

The visualization of geospatial position mainly includes map visualization, GIS visualization and graph visualization.

3.1.1 Map visualization: map means describing spatial elements with symbols, and using cartographic theory to express the representation of the earth on the plane. Map visualization is to express geospatial phenomena and laws by transforming geospatial location data into visible static twodimensional symbols. Figure 1 shows the global COVID-19 epidemic distribution map.

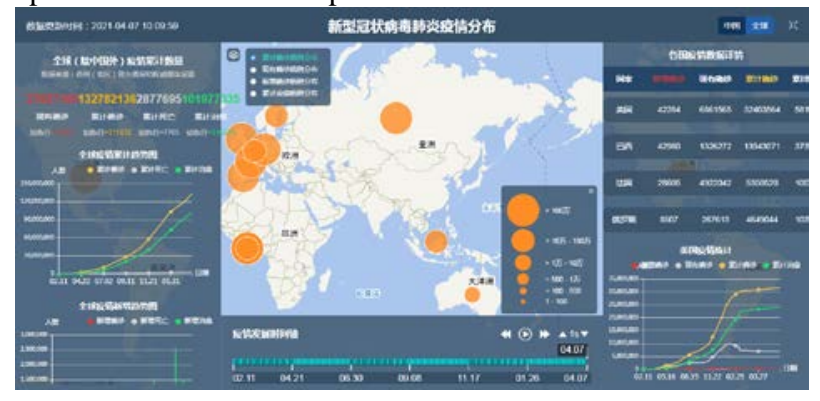

Figure 1. The global COVID-19 epidemic distribution map.

3.1.2 GIS visualization: Geographic Information System (GIS) is a technical system that collects, stores, manages, calculates, analyses, displays and describes the geographic distribution data in the whole or part of the earth's surface (including the atmosphere) with the support of computer hardware and software systems. GIS visualization focuses on geoseological data model and structure design, dynamic multidimensional data display, cultural and economic spatial regional data visualization, etc., and its visualization analysis results are also expressed in the form of maps.

3.1.3 Visualization of charts and graphs: graph visualization includes line graph, histogram, bar graph, pie graph, line graph, rectangular tree graph, curved surface graph, scatter graph, parallel coordinate graph and radar graph. Graph visualization includes density map, heat map, vector rectangular grid map, vector hexagonal grid map, linkage map and vector polygon thematic map. 


\subsection{Comprehensive services of industrial thematic geographic information}

Comprehensive services of industrial thematic geographic information integrates information sharing, data publishing and functional service. It also realizes the efficient and accurate collection of geographic information data from non-surveying and mapping geographic information industry sectors. Besides, it realizes the integrated application display of industrial thematic data and geospatial big data. For a long time, geographic information has been deeply applied in the fields of natural resources, water conservancy, transportation, public security, safety and emergency response, ensuring efficient and high-quality integrated industrial thematic geographic information services. Here are four examples:

Emergency industry: the National Emergency Early Warning Information Publishing Network comprehensively displays the early warning information of 76 emergencies in four categories of natural disasters, accidents and disasters, public health events and social security events. The Network provides accurate early warning information services for the state and the public, as shown in Figure 2.

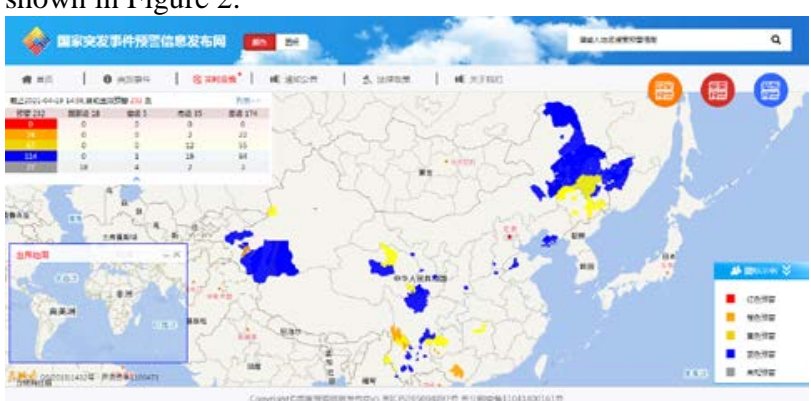

Figure 2. The National Emergency Early Warning Information Publishing Network map.

Meteorological industry: China Central Meteorological Observatory provides real-time weather information and services for 60,000 cities, towns, scenic spots, airports, islands, ski resorts and golf courses at home and abroad. Figure 3 shows the generation track and real-time location of typhoon No. 2102 SURIGAE on the typhoon website.
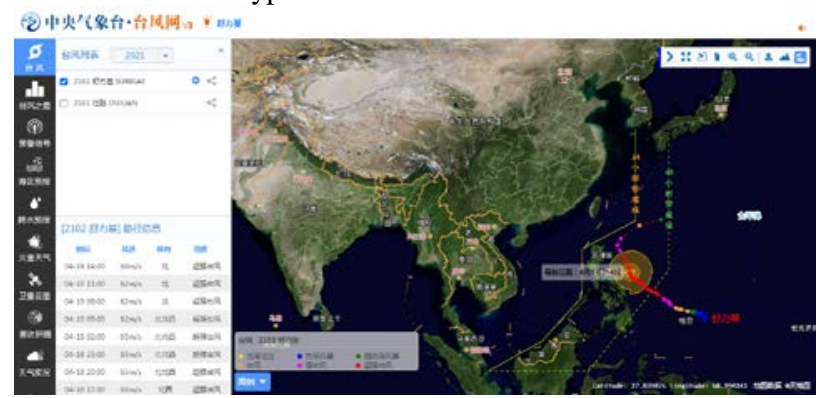

Figure 3. Generation track and real-time location of typhoon No. 2102 SURIGAE on the typhoon website.

Natural Resources industry: the geological cloud system portal which developed by the China Geological Survey of the Ministry of Natural Resources, integrates the massive geological survey data formed by the national geological work since the founding of the People's Republic of China-oil and gas, minerals, energy resources, mineral resources, as well as the scientific data of geological environment and geological disaster survey. Figure 4 shows the reserves and distribution of rare earth minerals on a scale of 1:500,000.

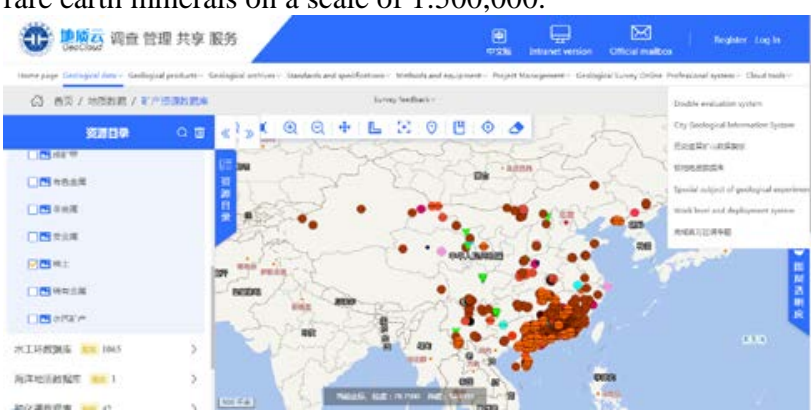

Figure 4. The reserves and distribution of rare earth minerals on a scale of 1:500,000 map.

Livelihood Economy: China Land Price Information Service Platform presents real-time data of land auction prices, land price monitoring indicators and transaction facts across the country, as shown in Figure 5.

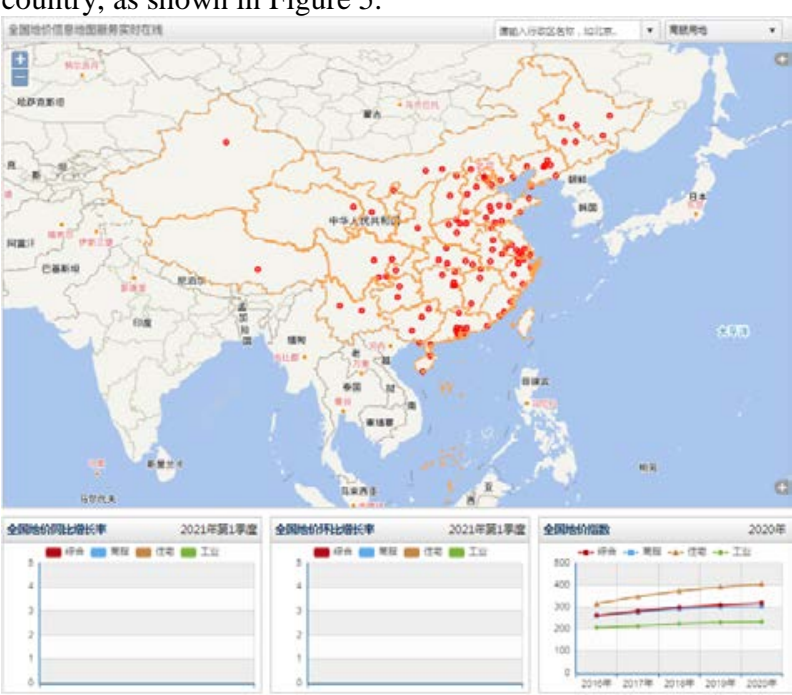

Figure 5. The National land price monitoring and trading reality map.

\subsection{Research on geographic data science and knowledge services}

As an important part of Earth big data, geospatial big data has always been highly concerned by researchers. The Earth Big Data Science Project led by academician Guo Huadong is based on Earth big data analysis, including geospatial big data, to study the association and coupling of the earth system, understand the complex interaction and evolution process between the earth natural system and human social system, and realize the Sustainable Development Goals (SDGs) (Guo Huadong et al., 2018).

Based on the background of spatio-temporal big data, Academician Chen Jun, a member of the team, discussed the connotation, times characteristics, structure and research direction of geographic knowledge engineering (Chen Jun et al., 2019a). Based on massive basic geographic data, they puts forward the general idea of basic geographic knowledge service with important features of structuralization and correlation, and takes GlobeLand30 (which is a set of high-resolution global land cover data products, covering the land range of 80 degrees north and south latitude, including 10 categories of land cover 
information, such as cultivated land, forest, grassland and shrub land) knowledge service as an example to introduce the preliminary research progress (Chen Jun et al., 2014). They also developed and launched geographic information professional knowledge service system. The system gathers the geographical information metadata professional literature, public version of basic geographic information data, basic geographic information resources directory, global surface coverage data, statistical analysis and structured, the spatial knowledge modelling and other data resources. The system also provides the latest public version of the geographic information data, thematic maps, free download service. A number of knowledge applications have been developed and put online to provide services of spatial association, mining, analysis and visualization of geographic information expertise. Chen Jun proposed a new method of monitoring and evaluating SDGs based on geographical data and spatial evidence, which is a comprehensive assessment of the progress of 2030 SDGS based on statistics and geographic information, and completed the world's first comprehensive assessment demonstration for the United Nations 2030 Agenda for Sustainable Development at county level in 2017 (Chen Jun et al., 2019b).

All in all, geospatial big data (including basic big data and applied big data) can obtain more useful value through data mining, knowledge discovery and visualization.

\section{DESIGN OF GEOSPATIAL BIG DATA PLATFORM}

With the further growth of geographic information engineering requirement, each project information system is independent from each other, leading to information silo and barrier, which seriously hinders the application of geospatial big data. The application of geospatial big data needs to be highly dependent on information system and integrated service platform. By building a one-stop geospatial big data platform, it can effectively break the information island and realize the highquality application of geospatial big data.

As an important component of the National Spatial Data Infrastructure, the geospatial big data platform should primarily meet the universality requirements of big data system construction, and at the same time meet the characteristics requirements of geospatial big data. At present, there are relevant Chinese National Standards (GB/T 38675-2020 and GB/T 38673-2020) that provide detailed provisions on hardware, software, network, security and other infrastructure, as well as basic functional and non-functional requirements of big data system. Secondly, a big data platform with geospatial application and public service attributes should be designed.

\subsection{Infrastructure requirements}

The geospatial big data platform infrastructure mainly includes hardware and software systems, networks and security systems that provide basic computing support for spatiotemporal big data storage, processing, analysis and application.

Hardware System: mainly including cell, unit of computing speed, storage unit, high-speed Internet and administrative supervision unit, power unit and structure unit and the cooling unit.

Software System: mainly including the operating system, virtualization software, resource management software and management software of communication.
Network System: have the ability to high availability and high consistency, scalability, and isolation.

Security System: should not be below the levels of network security protection level 3 requirements (GB/T 21028 and GB/T 37973-2019).

\subsection{Basic functional requirements}

The overall framework of geospatial big data platform function is shown in Figure 6. It mainly includes distributed storage and processing system, analysis system, data collection, preprocessing and visualization system and access management system.

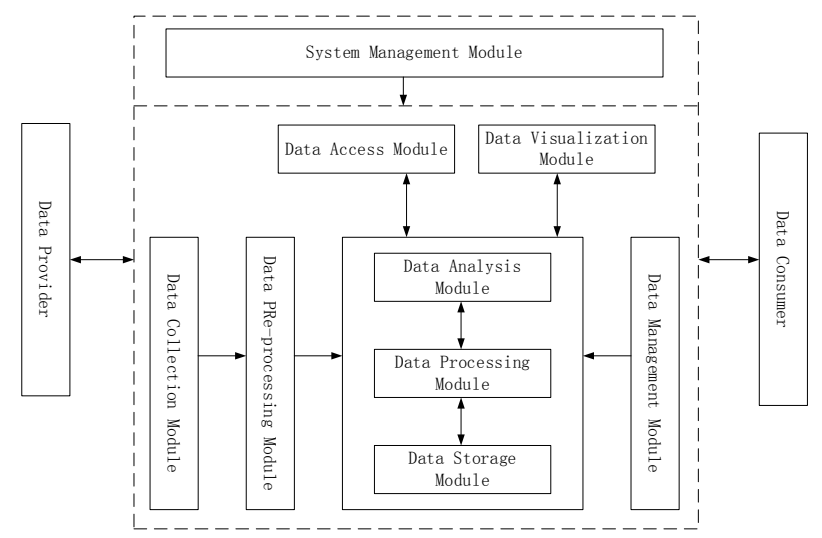

Figure 6. Overall functional architecture of geospatial big data platform.

4.2.1 Storage and Processing System (SPS): the spatiotemporal big data storage and processing system should include storage subsystem and processing subsystem. Common spatiotemporal big data storage and processing systems include HDFS, HBase and Postgres-XL. HDFS is the file system, the query ability is the weakest; HBase is built on HDFS, using column storage, for unstructured data and structured data has a strong query ability. Postgres-XL which is the most querycapable supports complex SQL queries.

Storage Subsystem: providing data storage function, support structured and unstructured and semi-structured data storage; provides the ability to exchange data or files with relational databases and other file systems; supports distributed file storage, distributed column data storage, distributed structured data storage and distributed graph data storage.

Processing Subsystem: supporting batch, stream processing, graph calculation framework; support memory computing, batch stream fusion computing framework; support for automatic scheduling of tasks based on dependencies between tasks.

4.2.2 Analysis System (AS): the temporal and spatial big data analysis system should support data query, machine learning, statistical analysis, offline data analysis, stream data analysis and spatial analysis; support interactive on-line analysis; support for visualize large screen display. This is shown in Table 1.

\begin{tabular}{|c|l|}
\hline Functions & \multicolumn{1}{|c|}{ Contents } \\
\hline Date Query & track, attributes, mesh, and area of the \\
\hline
\end{tabular}




\begin{tabular}{|l|l|}
\hline & query and summary \\
\hline $\begin{array}{l}\text { Spatial } \\
\text { Analysis }\end{array}$ & $\begin{array}{l}\text { spatial location, spatial distribution, } \\
\text { spatial relationships and spatial behaviour } \\
\text { and process }\end{array}$ \\
\hline $\begin{array}{l}\text { Statistical } \\
\text { Analysis }\end{array}$ & OD, hot and density analysis, etc. \\
\hline $\begin{array}{l}\text { Machine } \\
\text { Learning }\end{array}$ & $\begin{array}{l}\text { anomaly detection, filtering and similar } \\
\text { position elements connected }\end{array}$ \\
\hline $\begin{array}{l}\text { Flow Data } \\
\text { Analysis }\end{array}$ & convection data processing \\
\hline
\end{tabular}

Table 1. Functions of the AS.

4.2.3 Data collection, Pre-processing and Visualization system (DPV): data collection, pre-processing and visualization system are important parts of big data system. This is shown in Table 2.

\begin{tabular}{|l|l|}
\hline \multicolumn{1}{|c|}{ Functions } & \multicolumn{1}{|c|}{ Contents } \\
\hline $\begin{array}{l}\text { Data } \\
\text { Collection }\end{array}$ & $\begin{array}{l}\text { structured/unstructured/semi-structured/ } \\
\text { offline data import }\end{array}$ \\
\hline $\begin{array}{l}\text { Data Pre- } \\
\text { processing }\end{array}$ & $\begin{array}{l}\text { data extraction, data cleaning, line } \\
\text { structured data conversion, } \\
\text { transformation and table conversion, data } \\
\text { loading, etc. }\end{array}$ \\
\hline $\begin{array}{l}\text { Data } \\
\text { Visualization }\end{array}$ & $\begin{array}{l}\text { tables, histograms, pie charts, line charts, } \\
\text { heat map, etc. }\end{array}$ \\
\hline
\end{tabular}

Table 2. Functions of the DPV.

4.2.4 Access Management System (AMS): big data access management system includes data access, resource management and system management. This is shown in Table 3.

\begin{tabular}{|l|l|}
\hline \multicolumn{1}{|c|}{ Functions } & \multicolumn{1}{|c|}{ Contents } \\
\hline Data Access & access interface \\
\hline Resource & CPU, memory, scheduling and \\
Management & $\begin{array}{l}\text { configuration, the centralized } \\
\text { management of global resources, static } \\
\text { resource allocation strategy and dynamic } \\
\text { resource allocation strategy, resource } \\
\text { flexibility and grab, etc. }\end{array}$ \\
\hline $\begin{array}{l}\text { System } \\
\text { Management }\end{array}$ & $\begin{array}{l}\text { configuration management, tenant } \\
\text { management, monitoring alarm } \\
\text { management, service management, etc. }\end{array}$ \\
\hline
\end{tabular}

Table 3. Functions of the AMS.

\subsection{Non-functional basic requirements}

The non-functional requirements of geospatial big data platform mainly include reliability, compatibility, security, scalability, maintainability and ease of use.

Reliability: including support for high availability, data redundant storage and distribution of the data backup, recovery and migration, etc.

Compatibility: supporting compatible with different brand operating system.

Security: including support for user management, rights management, log management, data security, etc.

Scalability: including cluster expansion, online and offline capacity, capacity reduction function.

Maintenance: including providing installation deployment management, information system version, online upgrade system, fault diagnosis, all kinds of computing tasks running schedule, status of real-time tracking and reporting, and other functions.

Usability: including system installation configuration tool providing a graphical interface, and complete product documentation.

\subsection{An example of geospatial big data platform design}

At present, the National Platform for Common Geospatial Information Services as sharing and service portal of geographic information network, has integrated geographic information public service resources of the relevant government departments, enterprises, institutions, social organizations and public, which are from surveying and mapping geographic information departments at various levels (the national, provincial, municipal (county)). The National Platform provides various types of user authority, standard, unified online geographic information integrated service, as Figure 7 shown.

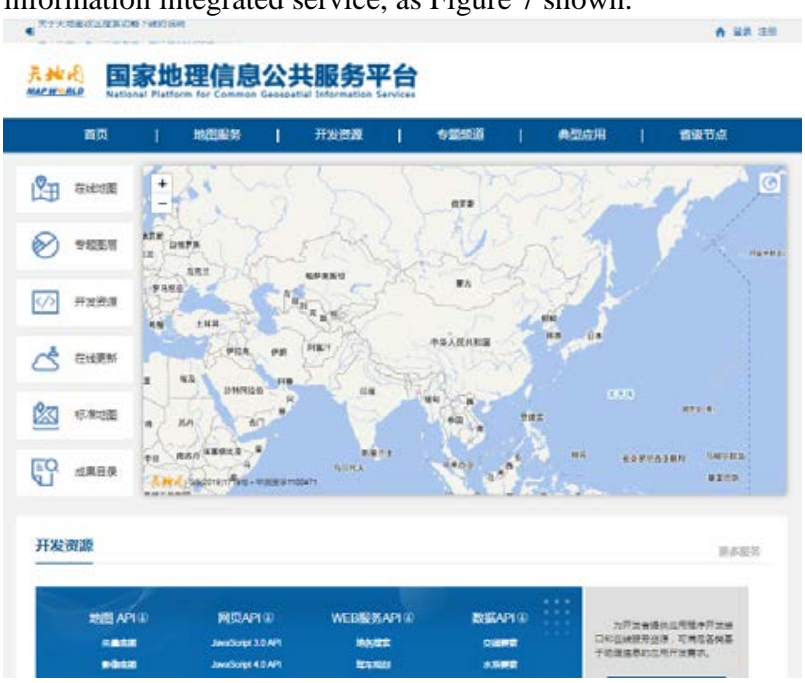

Figure 7. The portal of National Platform for Common Geospatial Information Services.

The value of geospatial big data lies in the application service, and the promotion of geospatial big data application and the provision of geospatial big data service are the important significance of the construction of geospatial big data platform. Therefore, the basic indicators of infrastructure, function and non-function of the big data platform for geographic information public service is shown in Table 4:

\begin{tabular}{|c|c|c|}
\hline Requirement & System & Design Index \\
\hline $\begin{array}{l}\text { Infrastructure } \\
\text { Requirements }\end{array}$ & $\begin{array}{l}\text { Hardware } \\
\text { System }\end{array}$ & $\begin{array}{l}\text { Each virtual server } \\
\text { specifications: CPU } \geqq 24 \\
\text { cores, memory } \geqq 96 \mathrm{~GB} \\
\text { memory, system disk } \geqq \\
200 \mathrm{~GB} \text { SSD storage of } \\
\text { ultra-high performance } \\
\text { computing services. Among } \\
\text { them, CPU frequency } \geqq \\
3.0 \mathrm{GHz} \text {, Intranet bandwidth } \\
\geqq \quad 12 \mathrm{Gbps} \text {, Intranet } \\
\text { receiving and sending } \\
\text { packet } \geqq 2 \text { million PPS, } \\
\text { disk IO read and write delay } \\
\leqq 1 \mathrm{~ms}\end{array}$ \\
\hline & $\begin{array}{l}\text { Software } \\
\text { System }\end{array}$ & $\begin{array}{l}\text { Support the virtual server to } \\
\text { mount } \geqq 20 \text { data disks, and }\end{array}$ \\
\hline
\end{tabular}




\begin{tabular}{|c|c|c|}
\hline & & $\begin{array}{l}\text { supports the anti-affinity } \\
\text { configuration of the virtual } \\
\text { server }\end{array}$ \\
\hline & $\begin{array}{l}\text { Network } \\
\text { System }\end{array}$ & $\begin{array}{l}\text { BGP shared bandwidth } \geqq \\
600 \text { Mbps, flexible public } \\
\text { network IP } \geqq 50 \text {, } \\
\text { enterprise-class VPC public } \\
\text { network gateway, maximum } \\
\text { number of } \quad \text { NAT } \\
\text { connections } \geqq 50,000 \text {, } \\
\text { provide NAT agent (SNAT, } \\
\text { DNAT), 10Gbps forwarding } \\
\text { capacity }\end{array}$ \\
\hline & $\begin{array}{l}\text { Security } \\
\text { System }\end{array}$ & $\begin{array}{l}\text { Enterprise or flagship } \\
\text { DDOS high protection, } \\
\text { Web application firewall, } \\
\text { host security, situational } \\
\text { awareness, database } \\
\text { security, fortress machine, } \\
\text { vulnerability scanning, etc., } \\
\text { through the network } \\
\text { security level protection } \\
\text { level } 3\end{array}$ \\
\hline \multirow[t]{4}{*}{$\begin{array}{l}\text { Basic } \\
\text { Functional } \\
\text { Requirements }\end{array}$} & SPS & 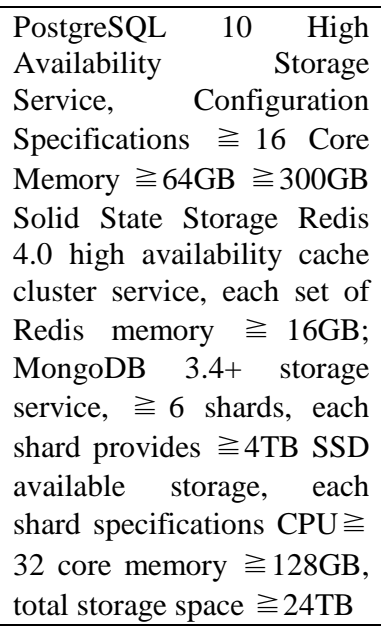 \\
\hline & AS & $\begin{array}{l}\text { Support full text retrieval } \\
\text { capability; Support spatial } \\
\text { object, spatial index and } \\
\text { spatial operation function } \\
\text { for geospatial big data }\end{array}$ \\
\hline & DPV & $\begin{array}{l}\text { Provide one-click function } \\
\text { of computing service image } \\
\text { creation, including system } \\
\text { disk image, machine image } \\
\text { and data disk image } \\
\text { enterprise-level data large } \\
\text { screen display services }\end{array}$ \\
\hline & AMS & $\begin{array}{l}\text { Provides efficient } \\
\text { collection, transmission and } \\
\text { distribution capabilities, } \\
\text { and the interface is } \\
\text { compatible with Kafka } \\
\text { native Producer/Consumer } \\
\text { API. Log storage and real- } \\
\text { time analysis of } 500 \text { million } \\
\text { to } 700 \text { million visits per day }\end{array}$ \\
\hline $\begin{array}{l}\text { Non- } \\
\text { functional } \\
\text { Basic } \\
\text { Requirements } \\
\end{array}$ & Reliability & $\begin{array}{l}\text { Provide the backup } \\
\text { capability of the whole } \\
\text { machine, you can choose } \\
\text { the backup time, backup }\end{array}$ \\
\hline
\end{tabular}

\begin{tabular}{|l|l|l|}
\hline & & cycle, retention rules \\
\cline { 2 - 3 } & Compatibility & $\begin{array}{l}\text { Distributed OS/database are } \\
\text { compatible with the } \\
\text { OS/database kernel engine } \\
\text { and client }\end{array}$ \\
\cline { 2 - 3 } & Security & $\begin{array}{l}\text { Support IP/Cookie/Referer } \\
\text { based multi-dimensional } \\
\text { CC protection }\end{array}$ \\
\cline { 2 - 3 } & Scalability & $\begin{array}{l}\text { Peak number of concurrent } \\
\text { users } \geqq 10,000\end{array}$ \\
\cline { 2 - 3 } & Maintenance & $\begin{array}{l}7^{*} 24-h o u r \text { cloud platform } \\
\text { monitoring and emergency } \\
\text { handling services }\end{array}$ \\
\cline { 2 - 3 } & Usability & $\begin{array}{l}\text { Provide training service } \\
\text { program }\end{array}$ \\
\hline
\end{tabular}

Table 4. The basic indicators of the big data platform for geographic information public service.

\section{CHALLENGES AND OPPORTUNITIES OF GEOSPATIAL BIG DATA}

\subsection{Open sharing of geospatial big data}

Due to historical reasons for China surveying and mapping geographic information institutions, surveying and mapping achievements of geographic information data scattered in local units which leads to big obstacles to the sharing of data and integration. Therefore, the opening and sharing idea of big data should be followed. We need to set up open geospatial large data sharing mechanism, and establish the geospatial data platform by means of distributed cloud computing technology. On the geospatial data platform, the massive, multi-source and heterogeneous geospatial data can realize collection, integration, processing and application.

The reference framework, specific requirements, openness degree evaluation system and evaluation indicators of government data openness and sharing are stipulated (GB/T 38664-2020). Its core is to build a unified metadata standard, including title, single identifier, category, description, data preview, revision history, license items, label, API authorization items, subsidiary items, etc. (Qian Xiaohong, 2014)

\subsection{Decision support for geospatial big data managements}

In September 2015, the UN Development Summit adopted the 2030 Agenda for Sustainable Development, which set out 17 Sustainable Development Goals (SDGs) and 169 specific targets covering economic, social and environmental fields. It calls on all countries to achieve coordinated development of economic growth, social inclusion and a better environment by 2030. The Ministry of Natural Resources cooperated with the People's Government of Deqing County in Zhejiang Province to carry out comprehensive monitoring and assessment based on statistics and geographic information in Deqing County as a pilot area, and finally formed the assessment results with "spatio-temporal coordinates" to help the government make accurate decisions and optimize the layout of public facilities (Chen Jun, 2019).

Since the institutional reform, with the depth of the surveying and mapping geographic information business into the Natural Resource Management "Two Unity", points and elements of the management system of grip are gradually broken. The geographical space data contributes to natural resource unified 
management, supporting unified platform for the decision of the management, and to promoting the modernization of natural resource governance capability.

\subsection{Security of geospatial big data}

The collection of massive geospatial data makes the internal links such as geospatial big data collection, storage and processing, mining and analysis, and application services face data security risks of data loss, tampering and illegal access. Therefore, data security should be considered from the perspective of the whole life cycle. As an important national strategic resource, geospatial big data faces severe threats to network information security, and its data security is related to national security. Therefore, the security of geospatial big data must be improved from the integration of infrastructure security, network communication security, computing storage and analysis security, management system security and operation and maintenance security of geospatial big data platform.

\section{CONCLUSION}

To sum up, with the continuous development of information technology, the opening up and sharing of geospatial big data is an inevitable trend. The construction of geospatial big data platform will play a greater role in social public-application service and the administrative management decision-making. In the future, it is necessary to carry out further researches on spatiotemporal big data mining, knowledge service, smart city and perception, etc. Besides, the application of geospatial big data will contribute to providing correct guidance and decisionmaking assistance for all walks of life.

\section{ACKNOWLEDGEMENTS}

The work was supported by National Key Research and Development Program of China (No. 2017YFB0503705).

\section{REFERENCES}

AI Tinghua. 2016: Cartography Development Driven by Big Data. Geomatics and Geomatics Information, 41(2), 1-7. https://doi.org/10.14188/j.2095-6045.2016.02.001.

Barik, Dubey, H. et al., 2016: FogGIS: Fog Computing for Geospatial Big Data Analytics. IEEE-Uttar-Pradesh-Section International Conference on Electrical, Computer, and Electronics Engineering (UPCON), 613-618.

Barik, Dubey, H. et al., 2019: GeoFog4Health: A Fog-based SDI Framework for Geospatial Health Big Data Analysis. Journal of Ambient Intelligence and Humanized Computing, 10(2), 551-567.https://doi.org/10.1007/s12652-018-0702-x.

Cai, H., S. et al., 2017: Using Multi-source Geospatial Big Data to Identify the Structure of Polycentric Cities. Remote Sensing of Environment, 202, 210-221. https://doi.org/10.1016/j.rse.2017.06.039.

Chen Jun, C., L. et al., 2014: The General Technology of Global 30m Land Cover Remote Sensing Mapping. Acta Geodaetica et Cartographica Sinica, 43(06), 551557.https://doi.org/10.13485/j.cnki.11-2089.2014.0089.

Chen Jun, L., W. et al., 2019a: Basic Issues and Research Directions of Basic Geographic Knowledge Service. Geomatics and Information Science of Wuhan University, 44(01), 3847.https://doi.org/10.13203/j.whugis20180441.

Chen Jun, P., Z. et al., 2019b: A Comprehensive Evaluation Method and Demonstration of Regional SDGs Considering Geospatial Perspective. Acta Geodaetica et Cartographica Sinica, 48(04), 473-479.

Deng X., L. et al., 2019: Geospatial Big Data: New Paradigm of Remote Sensing Applications. IEEE Journal of Selected Topics in Applied Earth Observations and Remote Sensing, pp (99), 111.https://doi.org/10.1109/JSTARS.2019.2944952.

Du Jiangyi, B., 2017: Overview of Spatial Data Mining for Big Data. Geospatial Information, 1, 8-11. https://doi.org/10.3969/j.issn.1672-4623.2017.01.003.

Guo Huadong, 2018: Geo-big Data Science and Engineering. Bulletin of Chinese Academy of Sciences, 33(08), 818-824. https://doi.org/10.16418/j.issn.1000-3045.2018.08.008.

Harvey J. M., Han J., 2009. Geographic Data Mining and Knowledge Discovery. London: CRC Press.

Huadong Guo, L., F. et al., 2014: Science Big Data and Digital Earth. Chinese Science Bulletin, 59(12), 1047-1054.

Jiang, Bin, 2014: Geospatial Analysis Requires a Different Way of Thinking: The Problem of Spatial Heterogeneity. Geojournal, 80(1), 1-13. https://doi.org/10.1007/s10708-014-9537-y.

Jiang B., Ren Z., 2019: Geographic Space as a Living Structure for Predicting Human Activities Using Big Data. International Journal of Geographical Information Science, 33(4), 764-779. https://doi.org/10.1080/13658816.2018.1427754.

Kramer, M., I., 2015: A Modular Software Architecture for Processing of Big Geospatial Data in the Cloud. Computers \& Graphics-UK, 49, 69-81. https://doi.org/10.1016/j.cag.2015.02.005.

Li Deren, C., 1995: Knowledge Discovery from GIS Database. Acta Geodaetica et Cartographica Sinica, 01, 37-44.

Li Deren, 2016: Prospects for Geospatial Informatics in the Big Data Era. Acta Geodaetica et Cartographica Sinica, 45(4), 379384. https://doi.org/10.11947/j.AGCS.2016.20160057.

Li Qingquan, L., 2014: Big Data GIS. Geomatics and Information Science of Wuhan University, 39(6), 641644.https://doi.org/10.13203/j.whugis20140150.

Liu Jiping, Z., W. et al., 2014: Research and Prospect of Big Data-oriented Spatial Information Decision Support Service. Science of Surveying and Mapping, 39(05), 812+17.https://doi.org/10.16251/j.cnki.1009-2307.2014.05.002.

Liu Jiping, Z., X., 2017: A Review of Government Geospatial Big Data Research. Acta Geodaetica et Cartographica Sinica, 46(10), 1678-1687. https://doi.org/10.11947/j.AGCS.2017.20170320.

Liu Yu, Z., Z. et al., 2018: Integration of Multi-source Geographic Big Data to Perceive Urban Spatial Differentiation Pattern. Geomatics and Information Science of Wuhan 
University, $\quad$ 43(03), 327-335. https://doi.org/10.13203/j.whugis20170383.

Lu Feng, Z., 2014: Big Data and Generalized GIS. Geomatics and Information Science of Wuhan University, 39, 645-654. https://doi.org/10.13203/j.whugis20140148.

Mccoy, MD., 2017: Geospatial Big Data and Archaeology: Prospects and Problems Too Great to Ignore. Journal of $\begin{array}{llll}\text { Archaeological } & \text { Science, } & \text { 84, }\end{array}$ https://doi.org/10.1016/j.jas.2017.06.003.

Mir, Abbasi, U. et al., 2018: Spatial Big Data and Moving Objects: A Comprehensive Survey. IEEE-Inst Electrical Electronics Engineers inc, 6, 58835-58857. https://doi.org/10.1109/ACCESS.2018.2874500.

Pei Tao, L., G. et al., 2019: The Essence of Geographical Big Data Mining. Acta Geographica Sinica, 74(003), 586-598.

Praveen, Babu, et al., 2016: Big Data Environment for Geospatial Data Analysis. International Conference on Communication and Electronics Systems (ICCES), 573-578.

Rumson, Hallett, SH., 2017: Coastal Risk Adaptation: the Potential Role of Accessible Geospatial Big Data. MARINE POLICY, 83, 100-110.

Shekhar, S., Jiang, et al., 2015: Spatiotemporal Data Mining: A Computational Perspective. Isprs International Journal of GeoInformation, 4(4), 2306-2338. https://doi.org/10.3390/ijgi4042306.

Soille, Burger, et al., 2018: A Versatile Data-intensive Computing Platform for Information Retrieval from Big Geospatial Data. Future Generation Computer Systems-The International Journal of Escience, 81, 30-40. https://doi.org/10.1016/j.future.2017.11.007.

Songnian Li, S. et al., 2015: Geospatial Big Data Handling Theory and Methods: A Review and Research Challenges. Isprs Journal of Photogrammetry \& Remote Sensing, 115, 119133.https://doi.org/10.1016/j.isprsjprs.2015.10.012.

Wang Shuliang, D., Z., 2013: Thinking on Spatial Data Mining under Big Data. Journal of China Academy of Electronic Sciences, 008(001), 8-17. https://doi.org/10.3969/j.issn.16735692.2013.01.002.

Zhou Chenghu, 2016: The Value of Spatial Data in the Era of Big Data-comment on Theory and Application of Spatial Data Mining. Acta Geographica Sinica, 26(7), 1904-1913. https://doi.org/10.1177/0959683616646187. 